\title{
Characteristics of the Dynamic Recrystallization Behavior of Ti-45Al-8.5Nb-0.2W-0.2B-0.3Y Alloy during High Temperature Deformation
}

\author{
Lin Xiang, Bin Tang *, Xiangyi Xue, Hongchao Kou and Jinshan Li \\ State Key Laboratory of Solidification Processing, Northwestern Polytechnical University, \\ Xi'an 710072, Shaanxi, China; xlin0731@163.com (L.X.); xuexy@nwpu.edu.cn (X.X.); \\ hchkou@nwpu.edu.cn (H.K.); ljsh@nwpu.edu.cn (J.L.) \\ * Correspondence: toby@nwpu.edu.cn; Tel.: +86-29-8846-0294
}

Received: 7 June 2017; Accepted: 4 July 2017; Published: 8 July 2017

\begin{abstract}
The dynamic recrystallization (DRX) behavior of Ti-45Al-8.5Nb-0.2W-0.2B-0.3Y (at \%) alloy has been investigated through hot compression tests. The tests were executed at a temperature range of $1000-1200{ }^{\circ} \mathrm{C}$ and a strain rate range of $0.001-1 \mathrm{~s}^{-1}$ under a true strain of 0.9 . It was found that the $\alpha_{2}$ phase which is produced during heat treatment is reduced during hot compression due to thermo-mechanical coupling. The value of the activation energy is $506.38 \mathrm{KJ} / \mathrm{mol}$. With the increase in deformation temperature and the decrease in strain rate, DRX is more likely to occur, as a result of sufficient time and energy for the DRX process. Furthermore, the volume fraction of high angle grain boundaries increases to $89.01 \%$ at a temperature of $1200{ }^{\circ} \mathrm{C}$ and the strain rate of $0.001 \mathrm{~s}^{-1}$, meaning completely dynamic recrystallization. In addition, DRX is related to the formation of twin boundaries. The volume fraction of twin boundaries rises to $16.93 \%$ at the same condition of completely dynamic recrystallization.
\end{abstract}

Keywords: titanium aluminides; hot compression; dynamic recrystallization; microstructure

\section{Introduction}

TiAl-based alloys are considered a promising candidate for high-temperature structural applications in the aerospace and automotive industries [1-4] because of their outstanding properties such as low density, high specific yield strength, high specific stiffness, good oxidation resistance and creep properties. However, natural brittleness, a key factor, limits the application of conventional TiAl-based alloys. In order to improve the hot workability of TiAl-based alloys, many studies have been performed over the last two decades [5,6]. It has been found that the addition of $\mathrm{Nb}$ can improve the workability of ductile $\beta / \mathrm{B} 2$ phase at elevated temperatures $[7,8]$, and $\mathrm{Nb}$ and $\mathrm{W}$ tend to enrich in $\beta /$ B2 phase, which contributes to the stability of $\beta /$ B2 phase [9].

It is commonly agreed that service properties are significantly connected with microstructures. It is also well-known that hot deformation is an effective method to optimize the microstructure, to further improve these properties. Dynamic recovery, phase transformations and DRX will occur during deformation at high temperature, resulting in the variation of size, morphology, fraction and distribution of phases [4,10-14]. Moreover, microstructure evolution is affected by hot deformation parameters, especially by deformation temperature, strain rate and degree of deformation $[15,16]$. The deformation behaviors of TiAl-based alloys of which the initial microstructure consists of the fully lamella or nearly lamella have been studied [17], indicating that the deformation mechanism of $\gamma$ phase is mainly DRX and that of $\alpha$ phase is dynamic recovery during deformation at $1275^{\circ} \mathrm{C}$. When strain reaches critical levels, the nuclei of DRX grains are generated, which will grow with increasing deformation degree [18]. The DRX mechanism of a TiAl-based alloy in a single $\alpha$-hcp phase 
region has also been investigated [19]. However, the phase transformation and DRX behavior of TiAl-based alloys with two $\beta+\gamma$ phases needs to be further characterized in detail.

The present paper studies the phase transformation and DRX behavior of a TNB (high $\mathrm{Nb}$ containing TiAl-based alloy) alloy with $\beta+\gamma$ two phases. For this purpose, the hot compression tests were conducted at different deformation temperatures and strain rates. The analysis of hot deformation behavior will be executed based on X-ray diffraction, microstructure and EBSD.

\section{Materials and Methods}

High-purity $\mathrm{Ti}, \mathrm{Al}, \mathrm{Nb}, \mathrm{W}, \mathrm{B}$ and $\mathrm{Y}(\geq 99.9 \%)$ were used as the raw materials. An ingot of TNB alloy with a nominal composition of Ti-45Al-8.5Nb-0.2W-0.2B-0.3Y (at \%) was fabricated using vacuum arc remelting (VAR melting) method, and the practical composition is listed in Table 1. Subsequently, the ingot was HIPed (hot isostatic pressed) at $1280{ }^{\circ} \mathrm{C}$ for $4 \mathrm{~h}$ under a pressure of $140 \mathrm{MPa}$. The dimension of the ingot after HIP is $\Phi 220 \mathrm{~mm} \times 190 \mathrm{~mm}$. In order to investigate hot deformation behavior, uniaxial compression tests were performed on a gleeble- 3500 thermo simulation machine. Cylindrical samples for compression tests with $8 \mathrm{~mm}$ in diameter and $12 \mathrm{~mm}$ in height were cut from the HIPed ingot, which deformed at temperatures ranging from $1000{ }^{\circ} \mathrm{C}$ to $1200{ }^{\circ} \mathrm{C}$ and strain rates from $0.001 \mathrm{~s}^{-1}$ to $1 \mathrm{~s}^{-1}$ under a true strain 0.9. To reduce the friction between two end sides of cylindrical sample and pressure heads of thermo simulation machine, graphite lubricant was adopted. Prior to deformation, samples were heated to target temperatures at a rate of $10 \mathrm{~K} / \mathrm{s}$, and then kept $300 \mathrm{~s}$ for uniformity of temperature. After the hot compression test, samples were quenched immediately to retain the deformed microstructure at elevated temperature.

Table 1. Chemical composition of present TiAl alloy.

\begin{tabular}{ccccccc}
\hline Element & $\mathbf{A l}$ & $\mathbf{N b}$ & $\mathbf{W}$ & $\mathbf{B}$ & $\mathbf{Y}$ & $\mathbf{T i}$ \\
\hline at $\%$ & 44.43 & 8.40 & 0.21 & 0.19 & 0.28 & Bal. \\
\hline
\end{tabular}

The initial microstructure after hot isostatic pressing is shown in Figure 1a. Phase composition is determined by XRD (in Figure 1b), which mainly consists of black $\gamma$ phase, white $\beta$ phase and gray $\alpha_{2}$ phase. The lamellar colony is composed of $\gamma$ lath and a small amount of $\alpha_{2}$ lath, which is surrounded by $\gamma$ and $\beta$ phase with the irregular morphologies. Some bright bulk particles are located in the lamellar colony, while others along the colony boundary were demonstrated to be impurities with B and Y elements [13], which are beneficial to decrease the size of the colony [20,21].

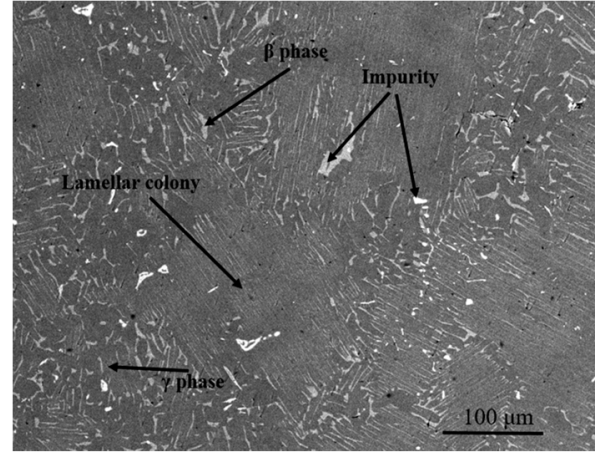

(a)

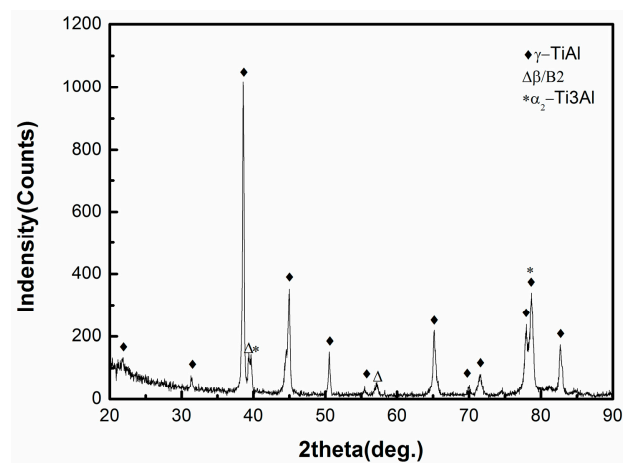

(b)

Figure 1. (a) The initial microstructure; and (b) X-ray diffraction pattern of HIPed alloy.

The microstructures were characterized via scanning electron microscopy (TESCAN, Brno city, Czech Republic) in the back scattered mode (SEM-BSE) and electron backscattered diffraction (EBSD). Dynamic recrystallization grains were investigated by EBSD which performed on TESCAN Field 
Emission Scanning Electron. The specimens for EBSD were prepared by Vibrational Polish for $8 \mathrm{~h}$. $\mathrm{X}$-ray diffraction were adopted to analyze the phases of alloy, which was carried out using $\mathrm{Cu} \mathrm{K} \mathrm{K}_{\alpha}$ radiation with $2 \theta$ range from $20^{\circ}$ to $90^{\circ}$, and the voltage, current and scanning step were $40 \mathrm{kV}, 30 \mathrm{~mA}$ and 0.03 , respectively.

\section{Results and Discussion}

\subsection{Analysis of Flow Curves}

\subsubsection{Characteristics of Flow Curves}

Figure 2 shows flow stress curves of the present TiAl alloy deformed at different deformation temperatures and strain rates. It is obvious that flow stress is sensitive to deformation temperatures and strain rates. With the increase of deformation temperature and the decrease of strain rate, flow stress decreases dramatically. With the increase of strain, flow stress reaches the peak value at the initial deformation stage, followed by flow softening. The softening stage of the present TiAl alloy persists for long time before reaching the steady-state regime. It is a typical characteristic of TiAl alloy that the deformation is dominated by DRX [22]. The critical strains of specimens deformed at different conditions are shown in Table 2. All values of critical strain are below 0.2. Such a low value indicates that the onset of DRX is very easy. With the decrease of strain rate, the value of critical strain gradually decreases, which indicates that DRX easily occurs at a low strain rate.

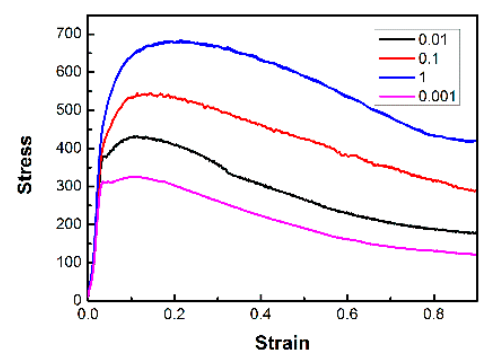

(a)

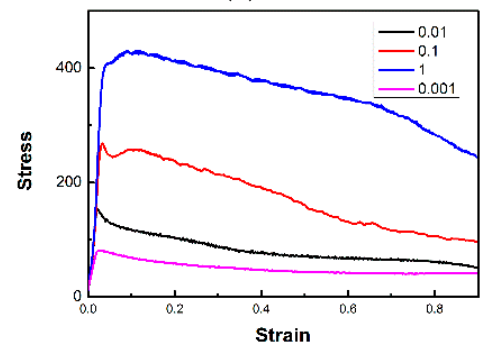

(d)

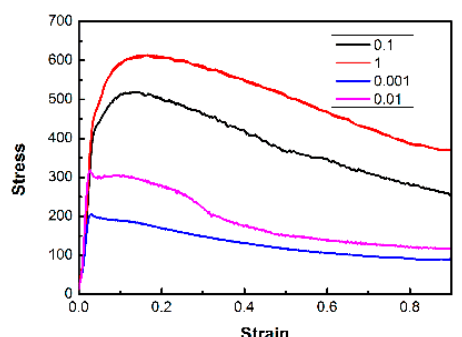

(b)

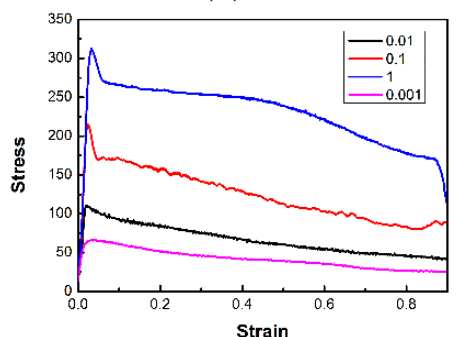

(e)

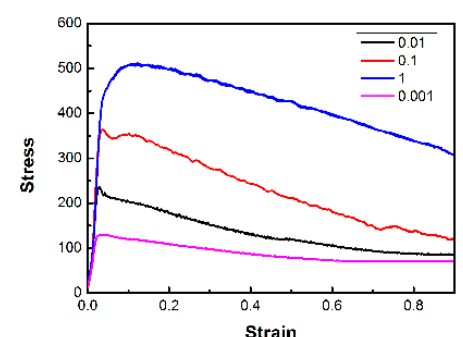

(c)

Figure 2. Flow curves of specimens deformed at (a) $1000{ }^{\circ} \mathrm{C}$; (b) $1050{ }^{\circ} \mathrm{C}$; (c) $1100{ }^{\circ} \mathrm{C}$; (d) $1150{ }^{\circ} \mathrm{C}$; (e) $1200{ }^{\circ} \mathrm{C}$.

Table 2. The critical strain of the present alloy deformed at different conditions.

\begin{tabular}{cccccc}
\hline Parameters & $\mathbf{1 0 0 0}{ }^{\circ} \mathbf{C}$ & $\mathbf{1 0 5 0}{ }^{\circ} \mathbf{C}$ & $\mathbf{1 1 0 0}{ }^{\circ} \mathbf{C}$ & $\mathbf{1 1 5 0}{ }^{\circ} \mathbf{C}$ & $\mathbf{1 2 0 0}{ }^{\circ} \mathbf{C}$ \\
\hline $0.001 \mathrm{~s}^{-1}$ & 0.05594 & 0.01272 & 0.01219 & 0.0136 & 0.00804 \\
$0.01 \mathrm{~s}^{-1}$ & 0.05747 & 0.01574 & 0.01651 & 0.01621 & 0.01039 \\
$0.1 \mathrm{~s}^{-1}$ & 0.06517 & 0.07555 & 0.01843 & 0.02057 & 0.01471 \\
$1 \mathrm{~s}^{-1}$ & 0.15034 & 0.12692 & 0.0619 & 0.08271 & 0.01828 \\
\hline
\end{tabular}




\subsubsection{Activation Energy $Q$}

Flow behavior of TiAl alloy can be well-described by the Arrhenius equation. The flow stress and deformation parameters can be expressed as

$$
Z=\dot{\varepsilon} \exp \left(\frac{Q}{R T}\right)=A[\sinh (\alpha \sigma)]^{n},
$$

For the different stress regime, Equation (1) can express it as follows:

$$
\begin{gathered}
\dot{\varepsilon}=B \sigma^{n^{\prime}}(\alpha \sigma<0.8), \\
\dot{\varepsilon}=B^{\prime} \exp (\beta \sigma)(\alpha \sigma>1.2),
\end{gathered}
$$

where $Q$ is activation energy, $n$ and $n^{\prime}$ are stress exponents, $\alpha, A, B$, and $B^{\prime}$ are material constants, and $R$ is the gas constant. The constant $\alpha$ can be calculated by Equation (4):

$$
\alpha=\beta / n^{\prime},
$$

Taking the logarithm of both sides of Equations (2) and (3), and linear curve fitting (Figure 3a,b), constants $\beta$ and $n^{\prime}$ can be worked out. It is important to note that the flow stress is taken at the peak strain in Figure 3. Then, constant $\alpha$ of the present alloy can be determined, and the value is $3.4 \times 10^{-3}$.

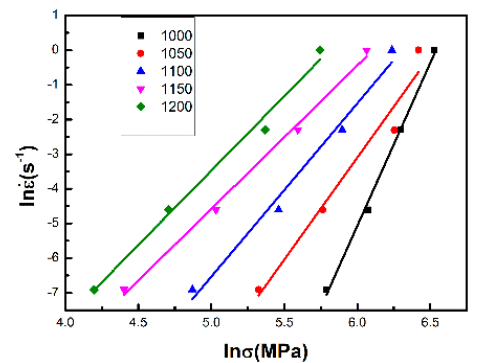

(a)

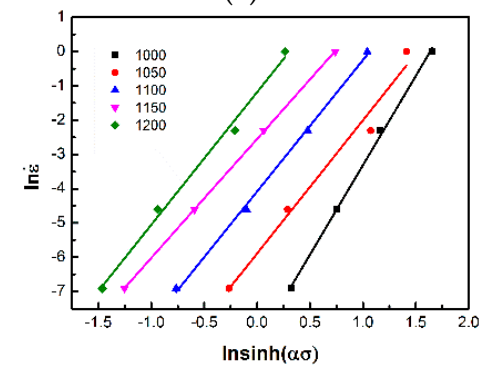

(c)

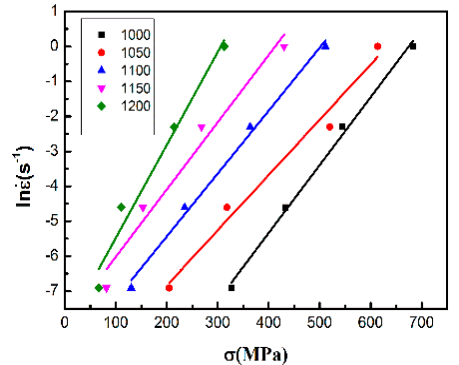

(b)

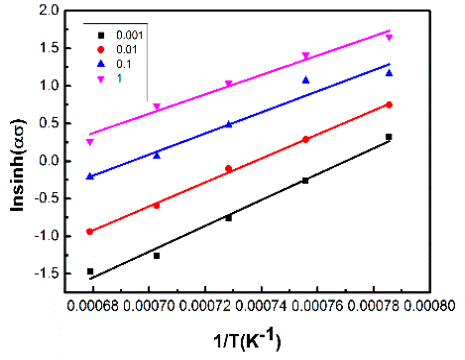

(d)

Figure 3. Plot of (a) $\ln \dot{\varepsilon}-\ln \sigma$; (b) $\ln \dot{\varepsilon}-\sigma$; (c) $\ln \dot{\varepsilon}-\ln [\sinh (\alpha \sigma)]$; (d) $\ln [\sinh (\alpha \sigma)]-1 / T$. It is important to note that the flow stress is taken at the peak strain.

The activation energy $Q$ can be calculated by Equation (5):

$$
Q=R\left\{\frac{\partial \ln \dot{\varepsilon}}{\partial \ln [\sinh (\alpha \sigma)]}\right\}_{T}\left\{\frac{\partial \ln [\sinh (\alpha \sigma)]}{\partial(1 / T)}\right\}_{\varepsilon},
$$

Taking logarithm of both sides of Equation (1), the slope of $\ln \dot{\varepsilon}-\ln [\sinh (\alpha \sigma)]$ and $\ln [\sinh (\alpha \sigma)]-1 / T$ curves can be obtained, as shown in Figure $3 c, d$. Thus, the value of activation energy $Q$ is $506.38 \mathrm{KJ} / \mathrm{mol}$, which is higher than activation energy for Ti self-diffusion $(260 \mathrm{KJ} / \mathrm{mol})$, Al self-diffusion $(390 \mathrm{KJ} / \mathrm{mol}$ ) and Ti-Al inter-diffusion $(295 \mathrm{KJ} / \mathrm{mol})$ in single $\gamma$-TiAl alloys [23-25]. 
Such a high value of activation energy $Q$ indicates that DRX appears in deformation and dominates the softening stage.

\subsection{Analysis of Microstructure}

Figure $4 \mathrm{a}$ is the $\mathrm{X}$-ray diffraction pattern of specimens deformed at the strain rate of $0.001 \mathrm{~s}^{-1}$ and heat treatment for $1200 \mathrm{~s}$. According to the binary phase diagram of TiAl alloy with 8 (at \%) $\mathrm{Nb}$ published in [26], $\alpha_{2}$ phase will be produced during heat treatment in the adopted temperatures. There are obvious peaks of $\alpha_{2}$ phase in heat treatment specimens. In Figure $4 b, c, \gamma$ phases, $\beta / B 2$ phases and $\alpha_{2}$ phases are represented by blue, red and yellow phases, respectively. Figure $4 \mathrm{~b}$ is the phase map showing the phase composition of specimen with solution at $1200{ }^{\circ} \mathrm{C}$ for $1200 \mathrm{~s}$. The yellow $\alpha_{2}$ phase can be observed clearly. Reversely, it is found that the peaks of $\alpha_{2}$ phase disappears in the compressed samples, which means that no $\alpha_{2}$ phase exists. Figure $4 c$, the phase map, also demonstrates that no yellow $\alpha_{2}$ phase exists. The result indicates that $\alpha_{2}$ phase, which is produced during heat treatment, is reduced during hot compression at the temperatures range of $1000-1200{ }^{\circ} \mathrm{C}$. TiAl-based alloy is a low stacking fault energy alloy, and for the present alloy, stacking fault energy further decreases on account of high $\mathrm{Nb}$ conditions [3]. Hence the onset of DRX happens more easily during hot deformation. The strain energy releases because of DRX, leading to a decrease in driving forces for producing $\alpha_{2}$ phase.

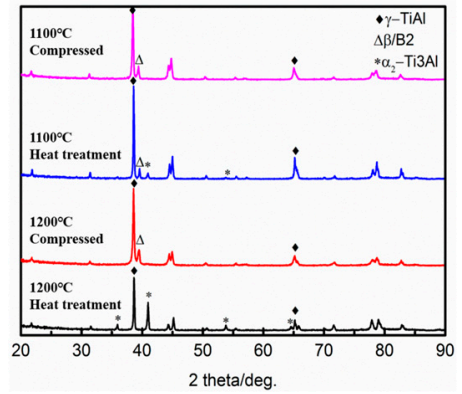

(a)

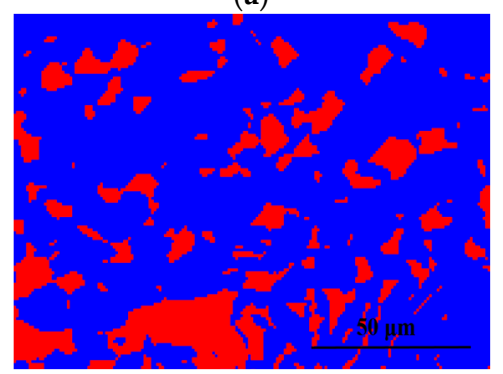

(c)

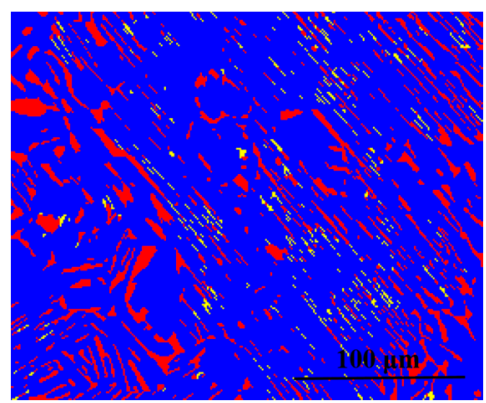

(b)

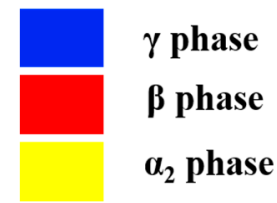

(d)

Figure 4. (a) X-ray diffraction patterns of specimens deformed at strain rate of $0.001 \mathrm{~s}^{-1}$ and heat treatment for $1200 \mathrm{~s}$; phase map corresponds to (b) heat treatment at $1200{ }^{\circ} \mathrm{C}$ for $1200 \mathrm{~s}$; and (c) deformed at $1200^{\circ} \mathrm{C}$.

Microstructures of deformed specimens at the strain rate of $0.01 \mathrm{~s}^{-1}$ and different temperatures ranging from $1000{ }^{\circ} \mathrm{C}$ to $1200{ }^{\circ} \mathrm{C}$ are shown in Figure 5. The $\beta$ phase uniformly distributes in $\gamma$ matrix. Elongated $\beta$ phase, perpendicular to the direction of compression, is distributed in $\gamma$ grain boundaries at the deformation temperature of $1000^{\circ} \mathrm{C}$. With the increase of temperature, a mass of elongated $\beta$ phases are broken and refined (in Figure $5 b, c)$. At a much higher deformation temperature, as shown in Figure $5 \mathrm{~d}, \mathrm{e}$, the morphology of $\beta$ phase gradually tends to be equiaxed and spherical. In addition, a vast number of $\gamma$ DRX grains are observed at all chosen temperatures. However, DRX process proceeds less effectively at a low temperature, which leads to the existence of primary coarse grains. On the other hand, the $\beta$ phase bends and distributes in $\gamma$ grain boundary at high strain rate, depicted in 
Figure 6a. Moreover, no DRX grains are observed. Instead, DRX grains are investigated obviously at low strain rate (Figure 6b). It is a common view that the short deformation time is caused by the high strain rate, which results in insufficient time for recrystallization.

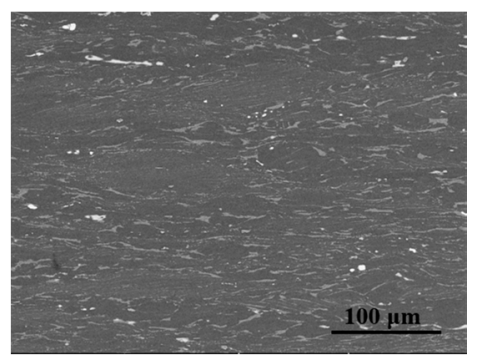

(a)

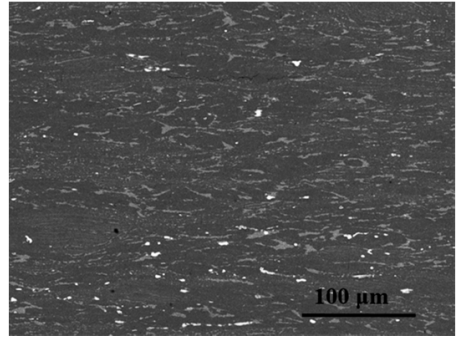

(b)

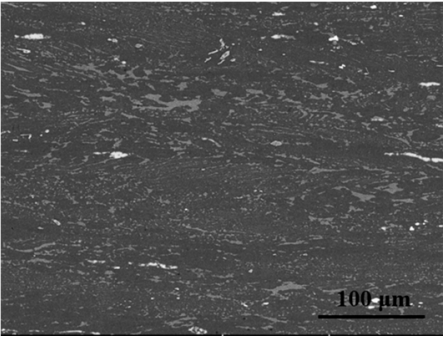

(c)

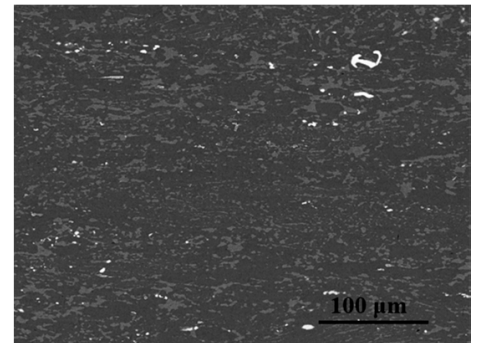

(d)

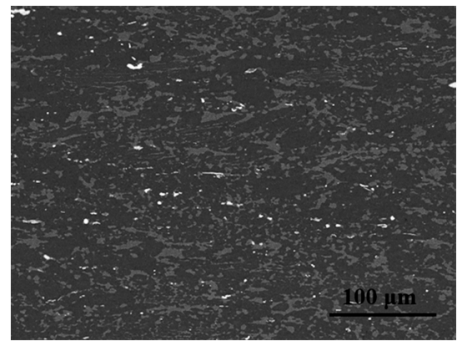

(e)

Figure 5. Microstructures of specimens isothermally deformed at the strain rate of $0.01 \mathrm{~s}^{-1}$ and different temperatures (a) $1000{ }^{\circ} \mathrm{C}$; (b) $1050{ }^{\circ} \mathrm{C}$; (c) $1100{ }^{\circ} \mathrm{C}$; (d) $1150{ }^{\circ} \mathrm{C}$; (e) $1200{ }^{\circ} \mathrm{C}$.

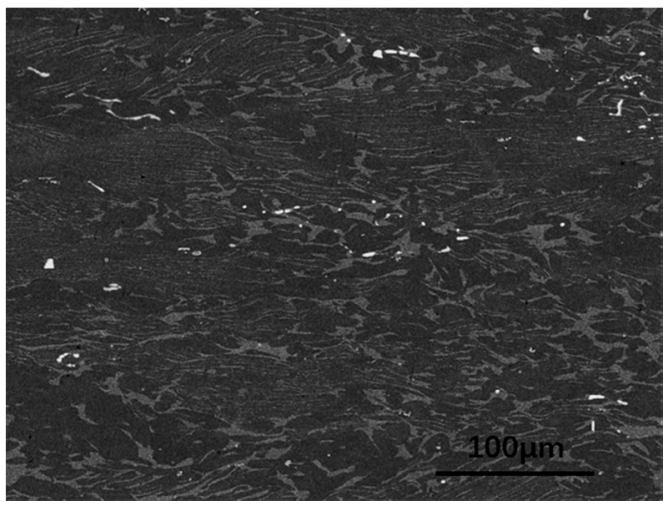

(a)

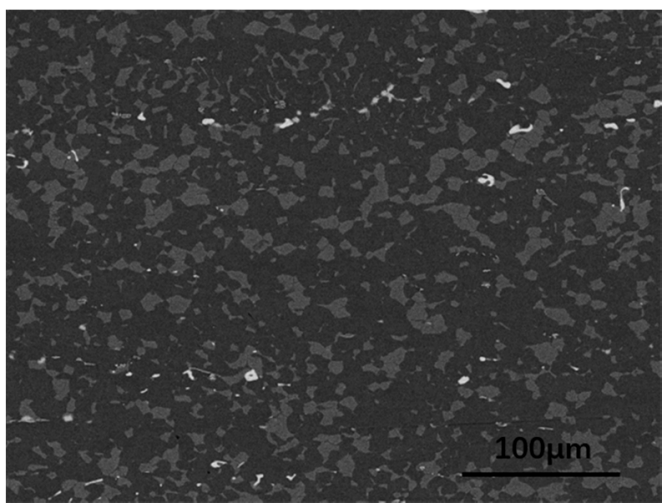

(b)

Figure 6. Microstructures of specimens isothermally deformed at the temperature of $1200{ }^{\circ} \mathrm{C}$ and different strain rates of (a) $1 \mathrm{~s}^{-1}$; (b) $0.001 \mathrm{~s}^{-1}$.

Figure 7, the IPF maps and grain boundary maps overlapped with phases, shows the characteristics of grains and grain boundaries in phases at different conditions. In the EBSD map images, $\gamma$ phases, $\beta /$ B2 phases and $\alpha_{2}$ phases are represented by blue, red and yellow phases, respectively. The black lines represent grain boundaries with a misorientation angle between $2^{\circ}$ and $15^{\circ}$, while the bright blue lines are used for a misorientation angle of more than $15^{\circ}$. Twin boundaries (TBs) with $57^{\circ} \leq \theta \leq 63^{\circ}$ are expressed by the pink lines. Generally, two types of grain boundaries, low angle grain boundaries (LAGBs) and high angle grain boundaries (HAGBs), are defined based on misorientation angles. The LAGBs are the typical feature of substructure forming during hot deformation, while HAGBs usually are caused by DRX and grains grow up via merging grains [27]. As is well known, grain boundaries with misorientation angle between $2^{\circ}$ and $15^{\circ}$ are LAGBs and those with orientation angle more than $15^{\circ}$ are HAGBs. 


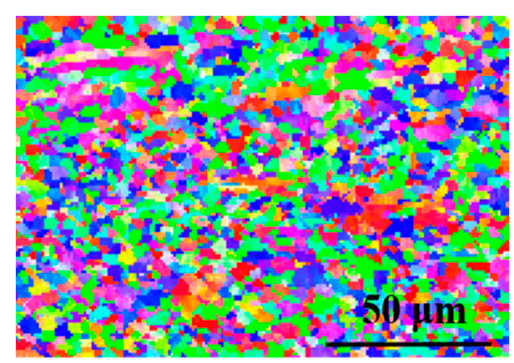

(c)

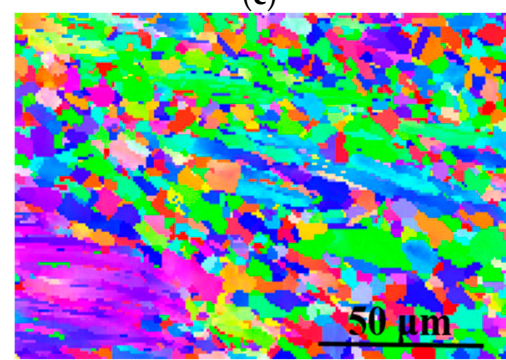

(e)

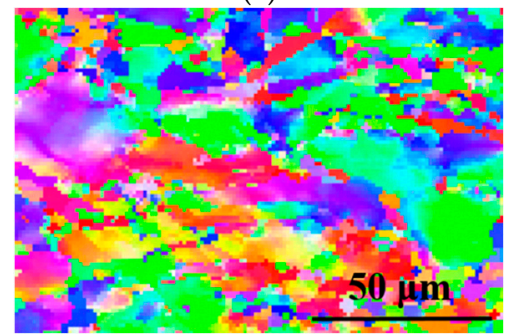

(g)

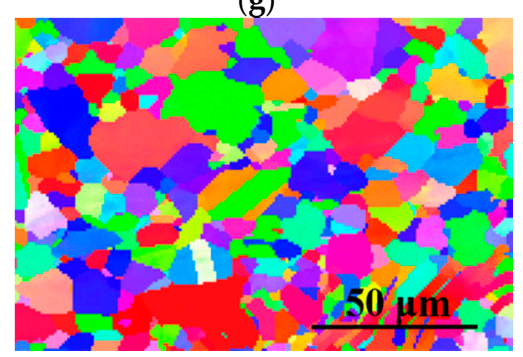

(i)

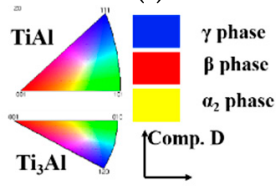

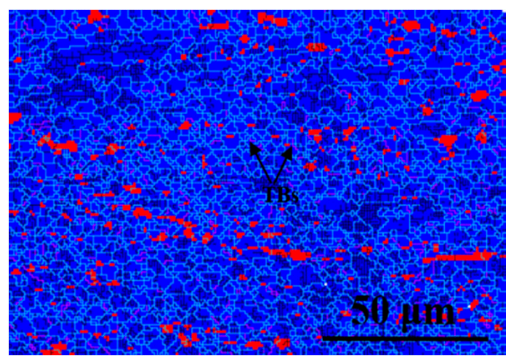

(d)

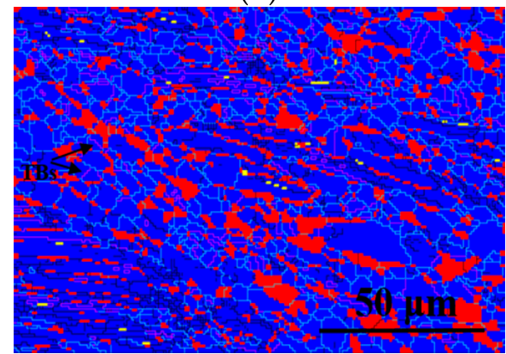

(f)

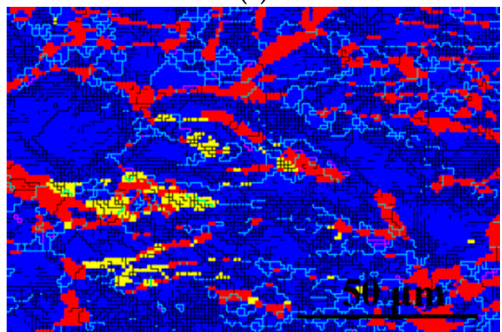

(h)

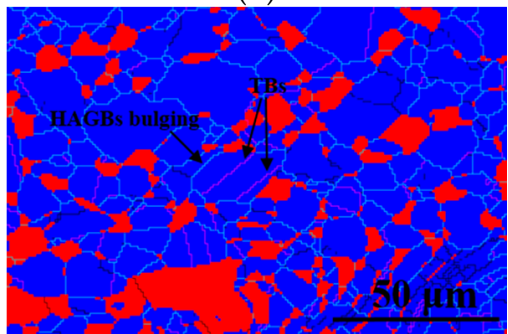

(j)

Grain boundary: misorientation angle

$\min \max$

$2^{\circ} \quad 15^{\circ}$

$60^{\circ} \pm 3^{\circ}<111>$

Figure 7. IPF maps and grain boundary maps overlapped with phases at different processing parameters: (a,b) $1000{ }^{\circ} \mathrm{C}, 0.01 \mathrm{~s}^{-1}$; (c,d) $1100{ }^{\circ} \mathrm{C}, 0.01 \mathrm{~s}^{-1}$; (e,f) $1200{ }^{\circ} \mathrm{C}, 0.01 \mathrm{~s}^{-1}$; (g,h) $1200{ }^{\circ} \mathrm{C}$, $0.1 \mathrm{~s}^{-1} ;(\mathbf{i}, \mathbf{j}) 1200{ }^{\circ} \mathrm{C}, 0.001 \mathrm{~s}^{-1}$.

In Figure 7a, a high number of fine and equiaxed $\gamma$ grains are observed, whereas coarse $\gamma$ grains still exist. Figure 7b shows the grain boundary map overlapped with phases which corresponds to Figure 7a. A large number of LAGBs can be investigated in coarse grains, which means coarse $\gamma$ grains are deformed primary grains. It can also be found that grain boundaries of fine and equiaxed grains in Figure 7a are HAGBs, proving that those grains are DRX grains. In general, DRX was divided into 3 types: (i) discontinuous dynamic recrystallization which comprises grain nucleation and grain growth, is usually observed in low stacking fault energy metals; (ii) continuous dynamic recrystallization which has been observed in high stacking fault energy metals; (iii) geometric dynamic recrystallization generated by the fragmentation of the initial grains [28]. High $\mathrm{Nb}$ containing TiAl-based alloy is low 
stacking fault energy alloy. Thus, the type of DRX is mainly discontinuous dynamic recrystallization in TiAl-based alloy. As deformation temperature increases to $1100{ }^{\circ} \mathrm{C}$ (Figure $7 \mathrm{c}, \mathrm{d}$ ), the number of $\gamma$ coarse grains with low angle decreases, and DRX grains are larger than those at the temperature of $1000{ }^{\circ} \mathrm{C}$. Figure 8 shows the distribution of misorientation angle at different conditions. As shown in Figure $8 \mathrm{a}, \mathrm{b}$, the fraction of HAGBs increases from $78.34 \%$ to $82.24 \%$. Because high temperature can provide DRX process with more active energy, which is beneficial to nucleation and growth of grains. Further raising deformation temperature to $1200^{\circ} \mathrm{C}$, a tiny number of $\gamma$ coarse grains with low angle can be observed (in Figure 7e,f), i.e., the extent of DRX is extremely high, but residual lamella still exists. The grain boundaries of $\beta$ grains are mainly HAGBs. In a word, as the deformation temperature arising, it is helpful for DRX process. It is worth noting that most of twin boundaries locate in DRX grains. Moreover, the area fraction of TBs is $2.67 \%$ at the deformation temperature of $1000{ }^{\circ} \mathrm{C}$, while it increases to $17.87 \%$ with the deformation temperature rising to $1200{ }^{\circ} \mathrm{C}$.

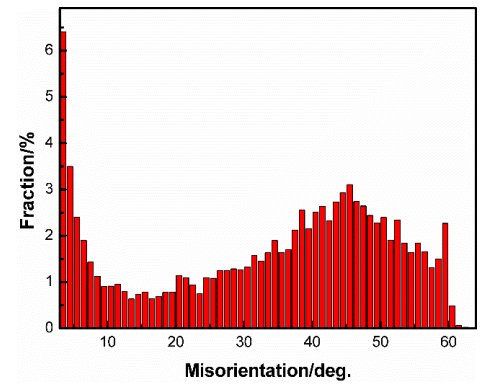

(a)

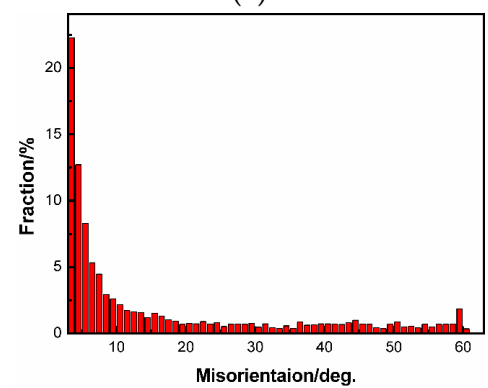

(d)

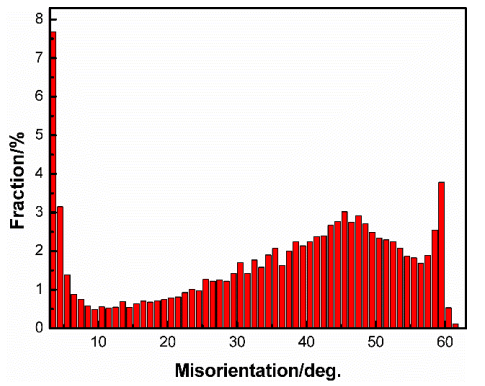

(b)

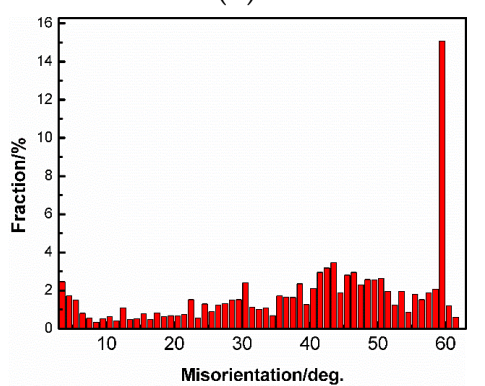

(e)

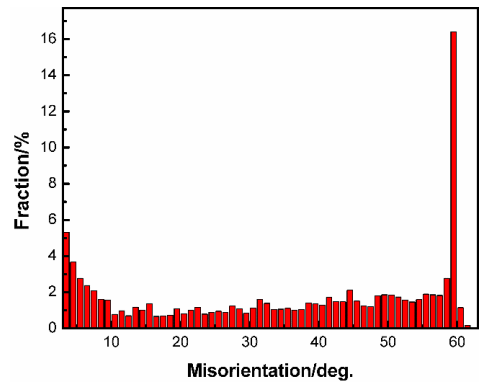

(c)

Figure 8. Misorientation angle distribution of deformed samples at different conditions: (a) $1000{ }^{\circ} \mathrm{C}$, $0.01 \mathrm{~s}^{-1}$; (b) $1100{ }^{\circ} \mathrm{C}, 0.01 \mathrm{~s}^{-1}$; (c) $1200{ }^{\circ} \mathrm{C}, 0.01 \mathrm{~s}^{-1}$; (d) $1200{ }^{\circ} \mathrm{C}, 0.1 \mathrm{~s}^{-1}$; (e) $1200{ }^{\circ} \mathrm{C}, 0.001 \mathrm{~s}^{-1}$.

As the strain rate increases to $0.1 \mathrm{~s}^{-1}$, a few DRX grains can be found in Figure $7 \mathrm{~g}$. The fraction of LAGBs and HAGBs are $66.92 \%$ and $33.08 \%$, respectively. Discontinuous dynamic recrystallization includes nucleation and growth processes of grains. The previous study has demonstrated that the nucleation process completes in a flash, while the growth process is overwhelmingly slow [22]. Deformation time is inadequate for DRX at high strain rate, and high temperature can activate a portion of slip system which benefits the formation of substructures. Therefore, the volume of LAGBs increased dramatically. Meanwhile, yellow $\alpha_{2}$ phase is observed in Figure 7h. Because driving force for producing $\alpha_{2}$ phase is not consumed completely by DRX. On the contrary, deformation time for DRX is guaranteed at the strain rate of $0.001 \mathrm{~s}^{-1}$, and completely DRX occurs during hot compression. As a result, the volume fraction of LAGBs drops dramatically to $10.99 \%$, and that of HAGBs increases to $89.01 \%$. It is difficult to find TBs surrounded by HAGBs in Figure 7h, and the volume of TBs is only about $1.69 \%$, depicted in Figure 8d. Reversely, a large number of TBs can be found at low strain rate as shown in Figure 7j, and the volume fraction of TBs increases to $16.93 \%$.

Interestingly, the majority of DRX grains are twin-related to the parent grains. The opposite grain boundaries of DRX grains are HAGBs and bulged. This phenomenon corresponds to previous studies in some alloys such as copper [29], and this twin-related nucleation mechanism is regarded 
as a typical feature of discontinuous DRX. Grain-boundary migrations are activated by high strain energy, followed by twin nucleation. The twins always generate within the parent grains, and opposite grain boundaries with misorientation angle more than $15^{\circ}$ migrate towards the neighboring grains. Moreover, the volume fraction of TBs increases with the enhancement of DRX extent, which also indicates that the formation of TBs is linked with discontinuous DRX.

\section{Conclusions}

In this study, uniaxial hot compression tests of Ti-45Al-8.5Nb-0.2W-0.2B-0.3Y alloy were carried out, and the results were analyzed using SEM, X-ray diffraction and EBSD techniques. Some conclusions drawn in this paper were as follows:

(1) Flow stress is sensitive to the temperature and strain rate. With an increase in temperature and a decrease in strain rate, flow stress decreases significantly. The critical strain is blow 0.2 , and the value of activation energy $Q$ is $506.38 \mathrm{KJ} / \mathrm{mol}$.

(2) $\alpha_{2}$ phase, produced during heat treatment, is reduced by thermo-mechanical coupling during hot compression. The yellow $\alpha_{2}$ phase can be observed clearly in a phase map of the heating treatment specimen. However, no yellow $\alpha_{2}$ phase exists in deformed specimen.

(3) With an increase in temperature and a decrease in strain rate, the extent of DRX increases. The volume fraction of HAGBs is $31.39 \%$ at the temperature of $1200{ }^{\circ} \mathrm{C}$ and the strain rate of $0.1 \mathrm{~s}^{-1}$, and that significantly rises to $89.01 \%$ at the strain rate of $0.001 \mathrm{~s}^{-1}$.

(4) Most DRX grains are twin-related to the parent grain. The formation of twins can promote the DRX process. The volume fraction of TBs is only $1.69 \%$ at the temperature of $1200{ }^{\circ} \mathrm{C}$ and the strain rate of $0.1 \mathrm{~s}^{-1}$, but that increases to $16.93 \%$ at the condition of completely DRX.

Acknowledgments: This work is financially supported by the Aeronautical Science Foundation of China (Project Number: 2015ZE53057) and the National key Research and Development Program of China (Project Number: 2016YFB0701303).

Author Contributions: Bin Tang and Jinshan Li conceived and designed the experiments; Lin Xiang performed the experiments; Xiangyi Xue and Lin Xiang analyzed the data; Hongchao Kou contributed reagents/materials/analysis tools; Lin Xiang wrote the paper.

Conflicts of Interest: The authors declare no conflict of interest.

\section{References}

1. Harding, R.A.; Wickins, M.; Wang, H.; Djambazov, G.; Pericleous, K.A. Development of a turbulence-free casting technique for titanium aluminides. Intermetallics 2011, 19, 805-813. [CrossRef]

2. Loria, E.A. Gamma titanium aluminides as prospective structural materials. Intermetallics 2000, 8, 1339-1345. [CrossRef]

3. Clemens, H.; Kestler, H. Processing and Applications of Intermetallic $\gamma$-TiAl-Based Alloys. Adv. Eng. Mater. 2000, 2, 551-570. [CrossRef]

4. Zhang, W.J.; Lorenz, U.; Appel, F. Recovery, recrystallization and phase transformations during thermomechanical processing and treatment of TiAl-based alloys. Acta Mater. 2000, 48, 2803-2813. [CrossRef]

5. Clemens, H.; Wallgram, W.; Kremmer, S.; Güther, V.; Otto, A.; Bartels, A. Design of novel $\beta$-solidifying TiAl alloys with adjustable $\beta$ /B2-phase fraction and excellent hot-workabilit. Adv. Eng. Mater. 2008, 10, 707-713. [CrossRef]

6. Clemens, H.; Chladil, H.F.; Wallgram, W.; Zickler, G.A.; Gerling, R.; Liss, K.D.; Kremmer, S.; Güther, V.; Smarsly, W. In and ex situ investigations of the $\beta$-phase in a $\mathrm{Nb}$ and Mo containing $\gamma$-TiAl-based alloy. Intermetallics 2008, 16, 827-833. [CrossRef]

7. Appel, F.; Oehring, M.; Wagner, R. Novel design concepts for gamma-base titanium aluminide alloys. Intermetallics 2000, 8, 1283-1312. [CrossRef]

8. Appel, F.; Oehring, M.; Paul, J. Nano-scale design of TiAl alloys based on beta phase decomposition. Adv. Eng. Mater. 2006, 8, 371-376. [CrossRef] 
9. Tang, B.; Cheng, L.; Kou, H.C.; Li, J.S. Hot forging design and microstructure evolution of a high $\mathrm{Nb}$ containing TiAl alloy. Intermetallics 2015, 58,7-14. [CrossRef]

10. Zghal, S.; Thomas, M.; Naka, S.; Finel, A.; Couret, A. Phase transformations in TiAl-based alloys. Acta Mater. 2005, 53, 2653-2664. [CrossRef]

11. Cui, N.; Kong, F.T.; Wang, X.P.; Chen, Y.Y.; Zhou, H.T. Hot deformation behavior and dynamic recrystallization of a $\beta$-solidifying TiAl alloy. Mater. Sci. Eng. A 2016, 652, 231-238. [CrossRef]

12. Huang, L.; Liaw, P.K.; Liu, Y.; Huang, J.S. Effect of hot-deformation on the microstructure of the Ti-Al-Nb-W-B alloy. Intermetallics 2012, 28, 11-15. [CrossRef]

13. Zhang, S.Z.; Kong, F.T.; Chen, Y.Y.; Liu, Z.Y.; Lin, J.P. Phase transformation and microstructure evolution of differently processed Ti-45Al-9Nb-Y alloy. Intermetallics 2012, 31, 208-216. [CrossRef]

14. Niu, H.Z.; Chen, Y.Y.; Kong, F.T.; Lin, J.P. Microstructure evolution, hot deformation behavior and mechanical properties of Ti-43Al-6Nb-1B alloy. Intermetallics 2012, 31, 249-256. [CrossRef]

15. Li, J.B.; Liu, Y.; Liu, B.; Wang, Y.; Cao, P.; Zhou, C.X.; Xiang, C.J.; He, Y.H. High temperature deformation behavior of near $\gamma$-phase high $\mathrm{Nb}$ containing TiAl alloy. Intermetallics 2014, 52, 49-56. [CrossRef]

16. Cheng, L.; Chang, H.; Tang, B.; Kou, H.C.; Li, J.S. Characteristics of metadynamic recrystallization of a high $\mathrm{Nb}$ containing TiAl alloy. Mater. Lett. 2013, 92, 430-432. [CrossRef]

17. Zhang, S.Z.; Zhang, C.J.; Du, Z.X.; Hou, Z.P.; Lin, P.; Kong, F.T.; Chen, Y.Y. Deformation behavior of high Nb containing TiAl-based alloy in $\alpha+\gamma$ two phase field region. Mater. Des. 2016, 90, 225-229. [CrossRef]

18. Cheng, L.; Chang, H.; Tang, B.; Kou, H.C.; Li, J.S. Deformation and dynamic recrystallization behavior of a high $\mathrm{Nb}$ containing TiAl alloy. J. Alloy. Compd. 2013, 552, 363-369. [CrossRef]

19. Wei, D.X.; Koizumi, Y.C.; Nagasako, M.; Chiba, A. Refinement of lamellar structures in Ti-Al alloy. Acta Mater. 2017, 125, 81-97. [CrossRef]

20. Li, B.H.; Chen, Y.Y.; Hou, Z.Q.; Kong, F.T. Microstructure and mechanical properties of as-cast Ti-43Al-9V-0.3Y alloy. J. Alloy. Compd. 2009, 473, 123-126. [CrossRef]

21. Chen, Y.Y.; Yang, F.; Kong, F.T.; Xiao, S.L. Microstructure, mechanical properties, hot deformation and oxidation behavior of Ti-45Al-54V-3.6Nb-0.3Y alloy. J. Alloy. Compd. 2010, 498, 95-101. [CrossRef]

22. Cheng, L.; Xue, X.Y.; Tang, B.; Kou, H.C.; Li, J.S. Flow characteristics and constitutive modeling for elevated temperature deformation of a high $\mathrm{Nb}$ containing TiAl alloy. Intermetallics 2014, 49, 23-28. [CrossRef]

23. Herzig, C.; Przeorski, T.; Mishin, Y. Self-diffusion in $\gamma$-TiAl: An experimental study and atomistic calculations. Intermetallics 1999, 7, 389-404. [CrossRef]

24. Mishin, Y.; Herzig, C. Diffusion in the Ti-Al system. Acta Mater. 2000, 48, 589-623. [CrossRef]

25. Sprengel, W.; Oikawa, N.; Nakajima, H. Single-phase interdiffusion in TiAl. Intermetallics 1996, 4, $185-189$. [CrossRef]

26. Witusiewicz, V.T.; Bondar, A.A.; Hecht, U.; Velikanova, T.Y. The Al-B-Nb-Ti system IV. Experimental study and thermodynamic re-evaluation of the binary Al-Nb and ternary Al-Nb-Ti systems. J. Alloy. Compd. 2009, 472, 133-161. [CrossRef]

27. Niu, H.Z.; Kong, F.T.; Chen, Y.Y.; Yang, F. Microstructure characterization and tensile properties of $\beta$ phase containing TiAl pancake. J. Alloy. Compd. 2011, 509, 10179-10184. [CrossRef]

28. Gourdet, S.; Montheillet, F. An experimental study of the recrystallization mechanism during hot deformation of aluminium. Mater. Sci. Eng. A 2000, 283, 274-288. [CrossRef]

29. Miura, H.; Sakai, T.; Mogawa, R.; Jonas, J.J. Nucleation of dynamic recrystallization and variant selection in copper bicrystals. Philos. Mag. 2007, 87, 4197-4209. [CrossRef]

(c) 2017 by the authors. Licensee MDPI, Basel, Switzerland. This article is an open access article distributed under the terms and conditions of the Creative Commons Attribution (CC BY) license (http:/ / creativecommons.org/licenses/by/4.0/). 